\title{
《o» 5eminar.пet
}

MEDIA, TECHNOLOGY \& LIFELONG LEARNING

\section{The impact of emotions on learning and motivation in producing and presenting digital stories.}

\section{Tor Jørgen Schjelde}

School of Business and Economics in Harstad

UiT The Arctic University of Norway

Email: tor.j.schjelde@uit.no

\section{Ingrid Nilsen Lie}

Department of Child Welfare and Social Work

UiT The Arctic University of Norway

Email: ingrid.n.lie@uit.no

\section{Abstract}

Researchers of digital storytelling emphasize emotions as an important aspect of learning in the production and presentation of digital stories. The aim of this study is to explore the positive and negative emotions involved in the process of making digital stories and presenting them. As well as students' perceptions of how this affects their motivation and learning. One hundred and thirty-two students responded to an adapted version of the Achievement Emotions Questionnaire, which collects data on the emotions present in a learning context. In addition, we interviewed ten students to gather in depth data about their feelings, motivation and learning. We found that both positive and negative emotions were involved when the students created and presented their digital stories. The students felt that their emotions influenced their motivation and learning. Drawing on theories of learning and motivation, we argue that negative activating emotions can aid learning, and positive deactive emotions can have a negative impact on learning. Emotions can aid 
The impact of emotions on learning and motivation in producing and presenting digital stories learning in higher education and digital storytelling is an important contribution in this regard.

Keywords: Digital storytelling, Learning, Emotion, Motivation

\section{Why considering students feelings?}

The emotions of child welfare students in encounters with children, adolescents and families during practice are important for their learning and professional development. We wish to examine how these emotions are experienced and applied when students produce digital stories from their practice, and what emotions they experience following their learning process. Does the sports commentator's question: "How do you feel now?" have any relevance to student learning? This will be explored in the present article, but let us first introduce the context of the study, child welfare education and training.

Child welfare programmes in Norway include one or more practice periods. Following their practice, students have various learning activities based on their practice. Child welfare students on the Harstad campus of UiT The Arctic University of Norway are required to produce digital stories and present them on film following their two practice periods.

The purpose of our study is to gain insight into the importance of students' emotions in the learning process of producing digital stories and presenting them on film. Students experience practice differently, and will also experience different emotional reactions. This emotional aspect of practice is difficult to capture in an academic text, but we assume that it can be expressed more clearly in a digital story. The background to our study is our desire to promote research-based teaching in the field of digital storytelling. Emotions are an important aspect of digital storytelling and our research is a contribution to the field. We will therefore explore the following research questions:

1. What positive and negative emotions are involved in the process of producing and presenting digital stories?

2. How do students find that these emotions influence their motivation and learning?

\section{Background to the study}

Digital stories are short, personal stories of 3-5 minutes in length that convey experienced events. The purpose is to provide the storyteller and listener with new insights (Lambert, 2010, 2013). Digital stories very often use still pictures more than video. The storyteller's voice, sounds and music accompany the pictures. This is done to emphasize the message of 
The impact of emotions on learning and motivation in producing and presenting digital stories the story. There are many possible themes, such as families, identity, relationships, oppression and injustice (Haug, Jamissen, \& Ohlmann, 2012; Lambert, 2010, 2013).

Digital storytelling is used as a learning tool in higher education to encourage students to reflect on different topics (Sandars \& Murray, 2011; Stacey \& Hardy, 2011). Anderson (2017) and Hardy (2017) emphasize that reflection is an important part of learning through digital storytelling. Nilsen Lie and Schjelde (2019) show that students learn through academic reflection on their own and others' practices when they create and share their stories.

In addition to reflection, emotions have been highlighted as a key aspect of digital storytelling, because students feel that they are emotionally engaged in the learning process. Through sharing their own stories, gaining insight into different topics, and being emotionally able to relate to other students' stories (Price, Strodtman, Brough, Lonn, \& Luo, 2015; Stacey \& Hardy, 2011). Digital stories differentiate from other types of expressions because the stories allows a connection with one`s feelings, makes students internalize narratives and engages them in learning (Kocaman-Karoglu, 2016). Students also expressed that digital stories supports practice learning, and enhances motivation because the work is personal, and making the stories inspires creativity (KocamanKaroglu, 2016).

Ribeiro, Moreira, and da Silva (2016) argues on how studentes reflection and display of emotion makes the learning process richer and deepens thinking. There is also evidence showing that the group work in digital stories has fostered more positive emotional experiences, and the researchers explain this because students support each other, and this causes less anxiety (Liu, Huang, \& Xu, 2018).

\section{Digital storytelling at our University}

Following their practice, students spend 3-4 days in a workshop, producing and presenting their stories. All students are asked to try to link theory and ethics to their story, and firstyear students create a story out of an event that has affected them during their practice. In the second year, students create a story that deals with their professional role as a child welfare officer. The difference between the first- and second-year stories is based on the content and progression of the curriculum.

Creation of the digital stories takes place in groups. This group work is called a "story circle" and represents a learning process in which students work to discover and develop their stories (Lambert, 2010). The goal of the story circle is to encourage joint reflection to provide individual students with insight into their stories and help in developing them. This is done through feedback provided by the other students in the group (Haug \& Jamissen, 2015). Our story circle methodology is based on The Seven Steps by Joe Lambert 
The impact of emotions on learning and motivation in producing and presenting digital stories (2013). In our story circle it has involved students freely sharing their ideas and receiving feedback from the other students. They then write down their story and return to the story circle for another round of feedback. Their teacher is present to provide advice and guidance. Students find pictures and music that fit the story and record the story in a digital medium. The order of pictures, music and the story itself is planned by using a storyboard or storyline. A storyline involves creating a timeline where the sequence of images, sound and other effects is planned. Students work independently on the storyline. Finally, all the elements are combined into a digital story, using the Movie Maker or iMovie filmmaking tools. The stories are then shown to the other members of the group, who provide mutual feedback.

\section{Theoretical framework: Emotions as indicators of learning}

Relationships between emotions and learning performance have received little attention (Govaerts \& Grégoire, 2008; Pekrun, Goetz , Titz , \& Perry 2002; Trigwell, Ellis, \& Han, 2012). In recent years, research has foucused on how emotions play a role in students' learning and development (Schjelde, 2015). The new concept of "academic emotions" has been developed to describe emotions related to learning and performance situations Pekrun et al. (2002) distinguish between four groups of emotions that are important for learning performance. These are:

1. Positive activating emotions, such as enjoyment of learning, hope of success and pride.

2. Positive deactivating emotions, such as relief or pleasant relaxation following success.

3. Negative activating emotions, such as anger, anxiety and shame.

4. Negative deactivating emotions, such as boredom and hopelessness.

Pekrun et al. (2002) find a correlation between positive activating emotions and motivation, effort, learning strategies that emphasize elaboration, and self-regulation. They assume that emotions and achievement mutually influence each other (Pekrun, Goetz, \& Perry 2014). If students initially show positive activating emotions, this will have a positive effect on their performance. The learning environment in the form of enthusiastic teachers, work requirements that students can meet on their own (autonomy), a goal structure that provides predictability, feedback and giving students a sense of belonging and a feeling of being supported can promote positive activating emotions. Here, there is also theoretical support in Deci and Ryan's theory of self-determination (Ryan \& Deci, 2012; Ryan, Deci, Fowler, Seligman, \& Csikszentmihalyi, 2000), which shows that people need to feel belonging, autonomy, and competence. Also, relevant here is Bandura's 
The impact of emotions on learning and motivation in producing and presenting digital stories theory of self-efficacy belief, which deals with faith in one's ability to organize or implement the necessary actions to learn at a particular level (Bandura, 1997). Schunk, Meece and Pintrich (2014) state that self-efficacy belief is important for students to experience control and self-determination. Further, self-efficacy belief has been shown to predict learning performance. Our self-efficacy belief is influenced by our experience of similar tasks in the past. If students have high self-efficacy belief, they will be more likely to make extra efforts when facing challenges, and less likely to give up, provided that they have the necessary skills (Bandura, 1997). Self-efficacy belief is linked to feelings of expectation about the outcome of a learning activity. According to Bandura (1986), students with high self-efficacy belief will usually also have high expectations of succeeding in a task. This leads to positive emotions such as hope of success and joy of learning, and the student will then feel highly motivated.

Negative deactivating emotions, such as boredom and hopelessness, are inversely related to intrinsic motivation, learning effort, self-regulation and concentration (Reinhard Pekrun, Goetz, Daniels, Stupnisky, \& Perry, 2010), and therefore have a potential negative effect on student learning The other two categories are more complex. A positive deactivating emotion may lead to reduced learning effort in the following task. Students may become over-confident and think that they do not have to make any effort this time. By contrast, negative activating emotions can motivate students to put in extra effort in the following classes, because they want to avoid a repeat of their negative feelings. Negative activating emotions such as anxiety are a natural and normal response to uncertainty (Nordhelle \& Sakhi, 2014). In unclear performance situations, where students get judged by others, it can lead to anxiety and insecurity. However, this process is necessary for learning to take place (Moxnes, 1989).

\section{Method}

In this section we present the methods we used to conduct and analyze our research.

Gerring (2007) points out that case studies provide a detailed exploration of a phenomenon and are used where case and context are difficult to distinguish. Case studies are also suitable for mixed data collection methods, and where a particular example is being studied. Drawing on Gerring (2007), we have chosen to present a case because we have studied child welfare students in their learning context and have used different methods to explore our research questions in depth. Child welfare students can also be considered an example.

We chose to use a questionnaire for our data collection because quantitative method was suitable to explore the positive and negative emotions present among a larger section of 
The impact of emotions on learning and motivation in producing and presenting digital stories informants, during the process of producing digital stories and presenting them on film. In the first instance, a questionnaire would provide relevant data on a relatively large number of respondents to capture "the big picture" of the phenomenon. We also conducted interviews to elicit greater detail, and to elaborate on how the students felt that their emotions influenced their motivation and learning.

This study was conducted among 132 first- and second-year students. Two first-year cohorts $(n=55)$ and three second-year cohorts $(n=77)$ completed the questionnaire. In addition, ten students were interviewed, five from each year. Students invited to interview were randomly selected by pulling students name randomly from student lists and asking them to participate in the interviews

\section{The questionnaire}

In order to collect data on emotions present in the learning context that may affect students' learning performance, we translated parts of the Achievement Emotions Questionnaire (R Pekrun, Goetz, \& Perry, 2005), which measures students' academic emotions. We translated statements that cover positive activating emotions $(\alpha=0.69)$, negative deactivating emotions $(\alpha=0.55)$ and negative activating emotions $(\alpha=0.64)$. We did not translate statements related to positive deactivating emotions because these emotions are a product of learning activities, and affect future action. We had no data on the students' future actions and therefore chose to exclude this area. In retrospect, we see that these emotions are relevant and should have been included. None of the areas in the questionnaire can be used as a common area, since internal reliability has a Cronbach's alpha $(\alpha)$ below 0.7. We therefore chose to present frequency tables in the results section. The responses in the questionnaire were measured on a five-point Likert scale, where $1=$ completely disagree and $5=$ completely agree with the statement.

\section{Interviews}

A semi-structured interview guide was prepared as the starting point for the interviews. The questions were based on the various parts of the storytelling component of the programme, such as the story circle and the creation and presentation of the story. Each student was asked about emotions, experiences, motivation and learning in relation to story circle, creation of and presentation of the digital story. The interview questions was not based on the questionnaire, but was designed to capture the students point of view in regards to the different parts of the process.

We used open coding to analyze the interview data, creating codes to express key themes in the data. These themes were: preparation, expectations, motivation, experience with the tool, the group process, emotions in relation to production and presentation, learning and feedback. We then classified statements on the same topic into categories and examined 
The impact of emotions on learning and motivation in producing and presenting digital stories common features of the statements within each category (Brinkmann \& Kvale, 2015). Each category reflects a key theme of the project. Brinkmann and Kvale (2015) state that theories can add new insights to the analysis, as long as the researcher is sensitive to different findings and angles in the interview data. Our final categories were as follows: expectations and self-efficacy, learning and the group process, and emotions.

\section{Limitations of the study and ethical considerations}

The questionnaire was handed out after the students had presented their digital story. They were informed about the purpose of the study and told that participation was voluntary and that they could withdraw at any time. The interviews were conducted after the students had completed the entire storytelling component of their programme.

One of the authors for this article helped to implement the storytelling component. This researcher developed the component and implemented it with the students. This may have influenced students' responses both in the questionnaire and in the interviews. The other researcher was not involved in teaching and interaction with the students. Against this background, both were involved in the distribution of questionnaires and the design of the interview guide to ensure open questions. The fact that a teacher researched and implemented a new educational intervention could be seen as a strength of the study (Anderson \& Shattuck 2012). At the same time, the dichotomy between active participation and maintaining a distance may be challenging (Reeves, 2011). A partnership between a teacher and a researcher has been argued to be important in ensuring validity (Anderson \& Shattuck 2012). Therefore, to minimize the impact on the results, both were actively involved in the analysis of the data and discussion of the findings.

A further limitation of the study is that we chose to omit positive deactivating emotions because our experience suggested that these emotions were not central to digital storytelling. In retrospect, we see that this dimension should have been included, since students mentioned this emotion in the interviews.

\section{Results}

We are now going to present the result of our research starting with the questionnaire responses. This section of the result gives us a general picture of the different emotion they experience when they produce and present their digital story.

\section{Questionnaire responses}

When we asked the students how satisfied they were with the teaching, 88\% expressed satisfaction. In the following presentation of the results, we have merged the responses "partly agree" and "completely agree" as "agree", and "partly disagree" and "completely disagree" as "disagree”. 
The impact of emotions on learning and motivation in producing and presenting digital stories Most students (65\%) reported positive activating emotions in creating and presenting their stories, $25 \%$ was uncertain and $10 \%$ disagree on statment about positive activating emotions. Most (75\%) believed that they would succeed, were optimistic during the storytelling component (68\%) and were proud of their contribution (65\%). This is illustrated here:

Table 1: Positive activating emotions

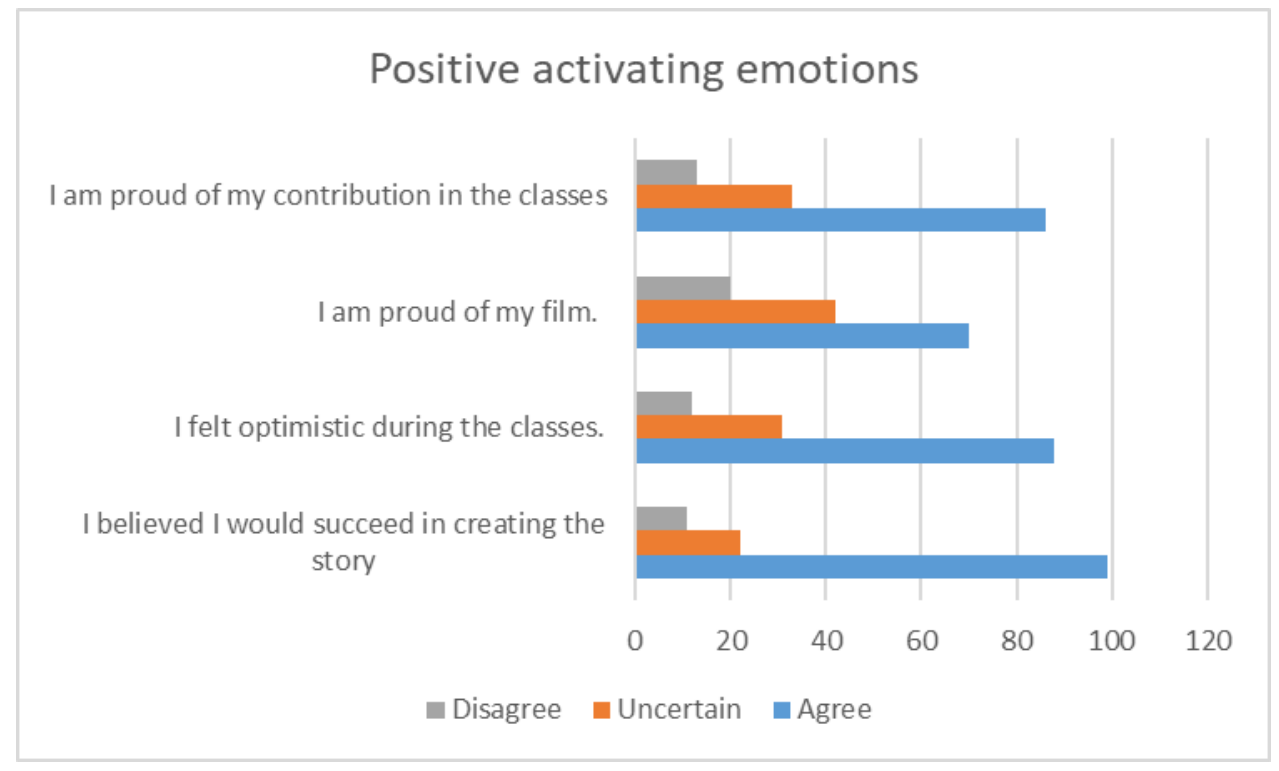

In regard to negative deactivating emotions, the results show that few students (15\%) reported negative deactivating emotions such as boredom during the classes. Of those who experienced such emotions, most reported not being motivated for these classes.

Table 2: Negative deactivating emotions

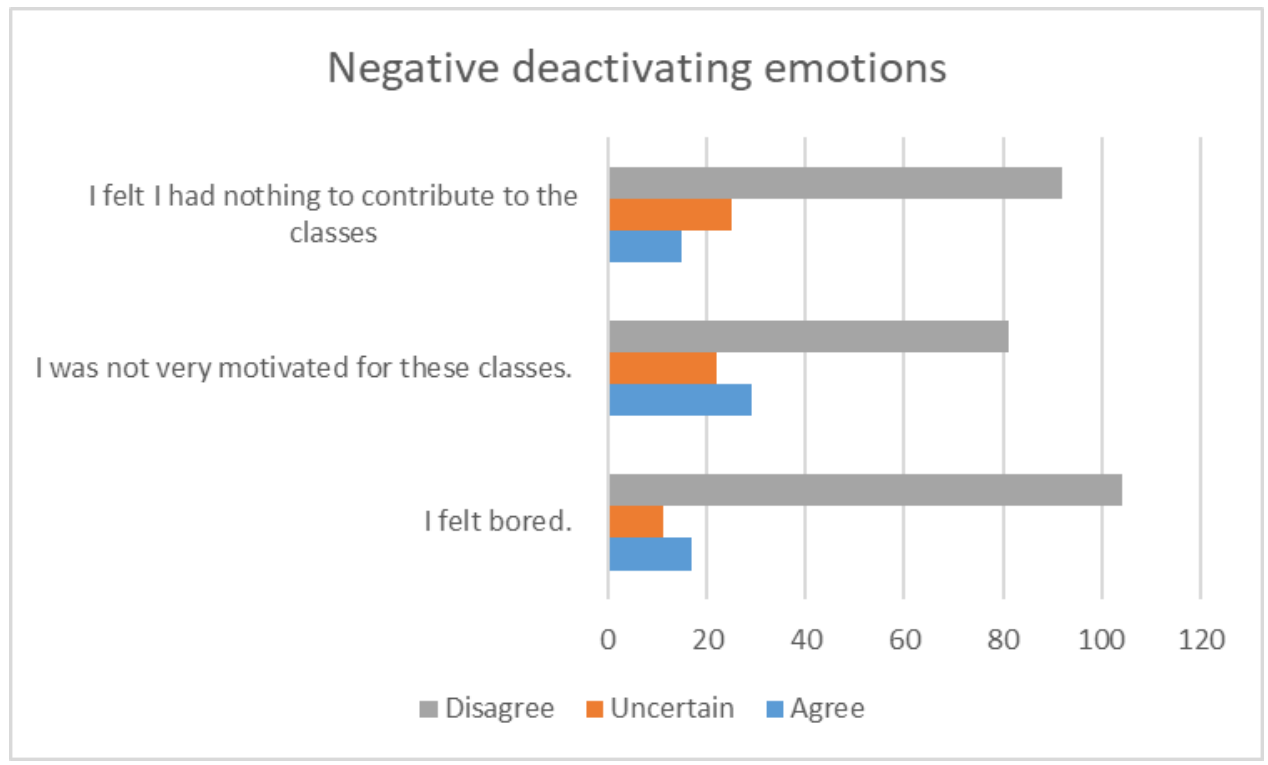


When it comes to negative activating emotions we get a more differentiated picture. $16 \%$ of the student experienced irritation or anger in the teaching setting. Few students (8\%) experienced negative activating emotions about speaking up in the groups. A majority of students (60\%) reported nervousness before and during the films, and a large proportion (47\%) were afraid of not succeeding.

Table 3: Negative activating emotions

\section{Negative activating emotions}

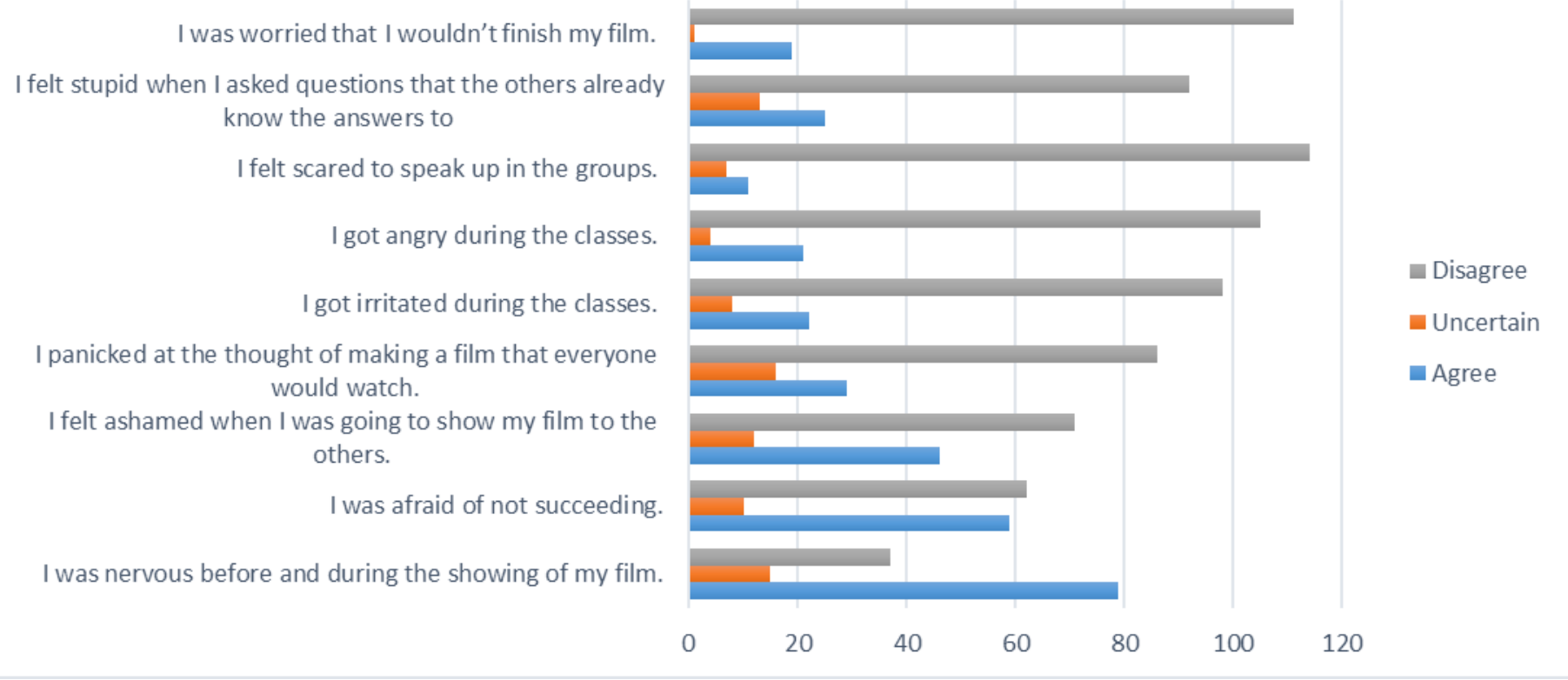

\section{The students' point of view from the interviews}

This section will present results from the interviews with the students in the categories: expectations and self-efficacy, learning and the group process, and emotions. The main categories are based on the theories of emotions, learning and motivation presented earlier in this article, and on the words of the students interviewed.

In the first category of "expectations and self-efficacy", the students reported having expected the classes to be fun, but had also been afraid of hearing their own voice. Some also reported being anxious because they had no experience of digital storytelling. The vast majority of students mastered the digital tool, but a few had challenges with the music or the editing of images and sound. Although a few experienced problems, they reported succeeding through trial and error.

In the second category: "emotions", most students described being embarrassed when 
The impact of emotions on learning and motivation in producing and presenting digital stories recording and hearing their own voice. Most felt nervous before they showed their digital story, but they all thought it was a success. A few students were annoyed and frustrated while working on their story. They reported being annoyed at receiving too little feedback from other students or because they were struggling with the tool they needed to use for storytelling. All students felt pleased at having managed to create a story and they felt good about watching the others' stories.

In the third category: "learning and group process" category, the students pointed out that they had gained knowledge of creating digital stories, showing them to others and using Movie Maker/iMovie. When students compared the learning outcomes of digital storytelling with practice assignments or group work based on problem-based learning, several of them felt that digital storytelling did not involve the same requirements for theory. They found it to be more experience-based. Several students also mentioned having to reflect on the event they wanted to make a story about, which was a learning experience. The students also found that there was much to learn and reflect on from watching each other's stories. Only one student thought that digital storytelling had no learning value, perhaps apart from learning to use the tool. Several of the students found that the group process was important for learning digital storytelling. However, there were examples of frustration when not all group members were equally motivated and involved in sharing and giving feedback on each other's stories. The frustration was based on poor feedback from the unmotivated students in the group. The students mentioned that it was important that peer feedback was constructive and pointed out both the good points of the stories and those aspects that could be improved.

\section{Analysis and discussion}

In the following we are going to present the analysis of the data and discuss our finds. Starting with positive emotions.

\section{Positive emotions and the learning process}

The students expressed positive activating emotions in the questionnaires, such as pride of their story, belief in success and optimism when working on digital stories. Such emotions can have a positive influence on student learning. Pekrun et al. (2002) state that positive activating emotions, such as the joy of learning, belief in success and pride, have been shown to have a positive effect on intrinsic and extrinsic motivation, effort and learning performance. This may be what was expressed by the students' experience in the interviews of mastering digital tools and learning through reflection when creating their own story and watching each other's stories. One student explained:

"I've learned a lot about myself and how it's ok to challenge myself. You reflect more on what happened when you sit down and make a story like that. You don't have to hold anything back, you actually learn from that as well. I've also learned how to use 
The impact of emotions on learning and motivation in producing and presenting digital stories digital tools."

The students' statements and experiences of their own learning reveal their positive emotions when they worked on their own and others' digital stories, and their feelings of having been motivated in preparing and presenting their stories. The following is one example of how they experienced emotions during the learning process in the interview material:

"I couldn't help smiling when I worked on my story. When the turning point came, I felt my feelings coming back linked to the experiences I'd had. The fact that he wouldn't talk to me or look at me. And that he didn't even want me to touch him. I felt all this when I was writing down all the feelings I'd had. I was completely at a loss in that situation. After the turning point, I felt the good feelings and I was happy. I thought, 'Wow, that's great, I managed to build a relationship!"”

The quote by this student is important to reflect on, based on the description of working on the narrative evokes emotions and memories in the student. This emotional aspect of practice is difficult to capture in an academic text, and as this quote shows the emotional side of practice is also powerful and important. Students' emotions related to practice will motivate them and inspire them to reflect, thus initiating and sustaining student learning. In line with Kocaman-Karoglu (2016) we also find that writing down the story allows a connection with one`s feelings and can be motivational because it is personal. The feelings in the memory and the process of writing down the personal reflection we think supports practice reflection. Reflecting means linking actions, theories, experiences and ethical considerations (Lauvås \& Handal, 2014). We might also suggest that reflecting should also include reflecting on the emotional side of the experience and actions and in line with Ribeiro et al. (2016) that argues that the display of emotion makes the learning process richer, and deepens thinking.

The students also reported in the questionnaires that they were optimistic and believed in their own success in digital storytelling. Having faith in one's own ability is referred to by Bandura (1997) as self-efficacy belief. This means trusting one can do what is necessary to get a job done. Self-efficacy belief is influenced by the experiences we have had with similar tasks in the past (Bandura, 1997). If students have had positive experiences with the use of Informating Technology in learning, this can have a positive impact on their self-efficacy belief. In the interviews, the students stated that they had positive expectations and were looking forward to creating digital stories, and although some experienced challenges in how to add music to their movie or editing the movie in movie maker, they still mastered the tool by trial and error. If students have high self-efficacy belief, they are more likely to increase their efforts when facing challenges, and to persevere if they have the necessary skills (Bandura, 1997). The students' optimism may also indicate that they expected a positive outcome of their work on digital storytelling. Optimism is associated with positive emotions and enhances student motivation (Bandura, 1986). 
The impact of emotions on learning and motivation in producing and presenting digital stories In spite of the students' positive expectations and mastery experiences, positive emotions can also be deactivating, such as relief, relaxation and pleasure. These emotions can lead to reduced learning, because the person believes that he/she does not have to put in as much effort. A feeling of pleasure can make the work seem less demanding, which will affect the learning effort. One student explained:

"You learn a number of other things when you write a practice assignment. You have to go much deeper into theory than you do in digital storytelling. I think a digital story is supposed to be more general, and a practice assignment should be more academic."

This statement suggests that digital storytelling may be too easy for students. It takes place in a comfort zone without major challenges. Learning is change in behaviour. To translate experience from practice into a digital story can be seen as a résumé rather than an important learning task. We have seen that most students expected to succeed in creating a digital story. Further, they felt that digital storytelling did not require theory, unlike a practice assignment, resulting in high self-confidence, a relaxed attitude and little effort put into digital storytelling. This again may mean fewer reflections in the story circle. We must be critical as to whether we achieve reflection at the desired level. Furthermore, we must realize that when students find lower requirements for theory in digital storytelling as in other types of student work, deactivating emotions may have arisen in the learning process. We also see that students found that some group members did not participate actively in the story circle. Pettersen (2017) writes that we have a general tendency to invest less effort when working in groups, and group members may experience loss of motivation because it is difficult to define the individual's efforts. This may be related to positive deactivating emotions where working in a group can make a person feel more relaxed about his/her own work. In the words of one of the students who found that not everyone in the group was equally motivated:

"It was difficult in the story circle that not everyone had a clear idea of what to write about and it was hard to get anything out of them. Not everyone was equally involved in the process or cared about it just as much. Not everyone was equally motivated and they never gave any feedback."

Peer feedback and students' learning experiences from digital stories will then affect students' emotions in the learning situation. Lack of feedback and learning efforts from other group members can make keen students bored, finding little meaning in the work.

In the next section, we will present negative emotions and their importance for student learning.

\section{Negative emotions and learning performance}

Negative deactivating emotions such as boredom and hopelessness have a negative impact 
The impact of emotions on learning and motivation in producing and presenting digital stories on student learning and can reduce intrinsic and extrinsic motivation (Pekrun et al., 2014). Some of the students reported being bored in the questionaire and unmotivated in the storytelling classes. This could be becase an important factor affecting student learning performance and motivation is autonomy. Creating digital stories is part of a mandatory work requirement in the programme. Students may therefore feel that participating in the group work and creating the story is an activity controlled by teachers, which they must do to avoid punishment, i.e. not meeting the work requirement. By contrast, an offer of choices can increase people's motivation (Deci, Vallerand, Pelletier, \& Ryan, 1991; Ryan \& Deci, 2012). For example, students choosing their own stories can provide a sense of autonomy, which may be strengthened by the feeling that the stories are based on their own experience and point of view. As one of the students experienced making a digital story in the interviews: "It lived up to my expectations. It was fun because I had the freedom to structure it the way I wanted."

We must also be aware that making demands on students does not necessarily mean that they experience weakened autonomy. What is important is the degree to which they accept these demands, how well they can meet the demands and whether they feel that they can influence the learning process.We think that the students feelt like they could meet our demands, because most students (88\%) reported that they were satisfied with the teaching.

With regard to negative activating emotions, $60 \%$ of the students felt nervous before and during the screening and some students felt ashamed or embarrassed when presenting their story. We know that negative emotions can have a negative effect on learning performance. $47 \%$ of students were afraid of failing in their attempt at digital storytelling. Low self-efficacy belief can lead to feelings such as hopelessness and sadness, which in turn can affect students' motivation for learning (Bandura, 1986). On the other hand, negative emotions in a learning situation do not necessarily mean less learning. Although the students reported nervousness before and during the presentation, this does not necessarily mean inferior learning. Negative activating emotions such as anger, anxiety or shame can motivate students to extra effort if the consequences of failure are great or to avoid the associated discomfort (Pekrun et al., 2002). Several of the students were nervous but were still satisfied and proud of their product reported in the questionnaire, which made their nervousness unimportant. Another factor is that our students work in groups during story circle. Group work can cause less anxiety and fostered more positive emotional experiences, because students support each other (Liu et al., 2018). Negative activating emotions such as anxiety are a natural response to uncertainty (Nordhelle \& Sakhi, 2014). Being nervous in performance situations is completely natural and can be seen as "warm anxiety" that provides energy and a signal that the performance is important. However, in some students, nervousness will lead to "cold anxiety", which will inhibit them in their performance (Moxnes, 1989, 2009). Since the students were presenting a digital story they had created in advance, the nervousness will not affect the presentation itself, but will affect the students' experience during the presentation. This is 
The impact of emotions on learning and motivation in producing and presenting digital stories shown by the fact that the students reported being nervous before presenting their stories on film. One student explained this as follows:

"I don't normally like presenting things, and it was even worse when I had to hear my voice out loud. It was almost better to listen to my voice than to physically stand up and read out loud. It wasn't that scary. If you've experienced the feeling of giving a presentation in front of some people, well, that's worse than having prepared it in advance, so everything's ready. Then you just press play.”

Negative activating emotions and warm anxiety should therefore not be pathologized. They can be important drivers of learning, indicating to the student the importance of making an effort.

\section{Summary reflection and further research}

Our study has examined the emotions involved in the learning context of producing and presenting digital stories. Teachers should be aware of the emotions present in a learning setting and how these can affect student learning and motivation. We have explored this by interviews and questionnaire. The students experienced positive activating emotions and expectations and motivation in relation to digital storytelling. The presence of positive emotions may not only enhance student learning, but make students realize that they have learned by reflecting on their own and others' experiences in practice. We believe that digital storytelling is an important contribution to post-practice reflection. Because we are creating what Pekrun et al. (2014) calls a good learning environment. Student reports high self-efficacy belief, they report feelings of success and pride in creating a digital story. The presence of positive emotions and motivation in the learning context will enhance student reflection, leading to greater learning outcomes.

We also see that students do not only experience positive emotions in the learning process. Most of them were nervous before and during the screening and some were afraid of failure. A few students were bored and unmotivated for digital storytelling, which might have adversely affected their learning. It seems it`s the dialectics or combination of paradoxical emotions that might lead to learning. As our research shows that even negative emotions can lead to learning. One factor to consider in relation to student learning in digital storytelling is that teachers have an important part to play in creating a safe learning environment. This also implies that the teacher has an important role to play in the story circle by being active and supporting students in the feedback process. These points are similar to those emphasized by Pekrun et al. (2002 ) as important for promoting positive activating emotions, which we know enhance student learning outcomes. All these factors will thus help to promote student learning. We must focus on the idea that students need to perceive themselves as competent in order to be motivated in their work. This is related to Bandura's concept of self-efficacy belief, which means having faith in one's 
The impact of emotions on learning and motivation in producing and presenting digital stories ability to organize or implement the actions that are necessary to learn at a certain level (Bandura, 1997).

Further work on digital storytelling should explore how feedback can influence emotions and increase student learning in the use of digital stories. Another interesting angle would be to study how students' emotions affect their learning performance in terms of assessing the content of the digital stories. We believe that digital stories as a teaching and learning method allow students to work with subject matter in a way that can foster positive emotions, and with the right support also can make negative emotions become positive in the sense of learning. The research is a part of developing higher education towards the digital storytelling University (Jamissen \& Haug, 2014) where also emotions plays a central role. So the sports commentator`s question: "How do you feel now?", have important relevance also in academic learning.

\section{References}

Anderson, K. M. (2017). Let's Get Personal: Digital Stories for Transformational Learning in Social Work Students. In G. Jamissen, P. Hardy, Y. Nordkvelle, \& H. Pleasants (Eds.), Digital Storytelling in Higher Education: International Perspectives (pp. 7389). Springer International Publishing. https://doi.org/10.1007/978-3-319-51058-3 6

Anderson , T., \& Shattuck , J. (2012). Design-based research a decade of progress in education research? Educational researcher, 41(1), 16-25. https://doi.org/10.3102/0013189X11428813

Bandura, A. (1986). Social foundations of thought and action : a social cognitive theory. Prentice-Hall.

Bandura, A. (1997). Self-efficacy : the exercise of control. Freeman.

Brinkmann, S., \& Kvale, S. (2015). InterViews : learning the craft of qualitative research interviewing (3rd ed. ed.). Sage.

Deci, E. L., Vallerand, R. J., Pelletier, L. G., \& Ryan, R. M. (1991). Motivation and Education: The Self-Determination Perspective. Educational Psychologist, 26(3-4), 325-346. doi:10.1080/00461520.1991.9653137

Gerring, J. (2007). Case study research: principles and practices. Cambridge University Press. https://doi.org/10.1017/CBO9780511803123

Govaerts, S., \& Grégoire, J. (2008). Development and Construct Validation of an Academic Emotions Scale. International Journal of Testing, 8(1), 34-54.

doi:10.1080/15305050701808649

Haug, K. H., Jamissen, G., \& Ohlmann, C. (2012). Digitalt fortalte historier : refleksjon for læring. Cappelen Damm akademisk. 
The impact of emotions on learning and motivation in producing and presenting digital stories Jamissen, G., \& Haug, K. H. (2014). Towards the digital storytelling university. In C. Gregori-Signes \& A. Brìdigò Corachàn (Eds.), Appraising digital storytelling across educational contexts (pp. 93-113). University of Valencia Press.

Kocaman-Karoglu, A. (2016). Personal voices in higher education: A digital storytelling experience for pre-service teachers. Education and Information Technologies, 21(5), 1153-1168. doi:10.1007/s10639-014-9373-1

Lambert, J. (2010). Digital storytelling cookbook. Digital Diner Press.

Lambert, J. (2013). Digital storytelling: capturing lives, creating community (4th ed. ed.). Routledge. https://doi.org/10.4324/9780203102329

Lauvås, P., \& Handal, G. (2014). Veiledning og praktisk yrkesteori (3.ed.). Cappelen Damm akademisk.

Liu, M.-C., Huang, Y.-M., \& Xu, Y.-H. (2018). Effects of individual versus group work on learner autonomy and emotion in digital storytelling. Educational technology research and development, 66(4), 1009-1028. doi:10.1007/s11423-018-9601-2

Moxnes, P. (1989). Hverdagens angst i individ, gruppe og organisasjon : et organisasjonspsykologisk perspektiv. P. Moxnes.

Moxnes, P. (2009). Hva er angst (Vol. 32). Universitetsforlaget.

Nilsen Lie, I., \& Schjelde, T. J. (2019). Læring og narrativer: digitale fortellinger fra praksis. Tidsskriftet Norges Barnevern (01-02), 104-116. doi:10.18261/ISSN.18911838-2019-01-02-08

Nordhelle, G., \& Sakhi, U. S. (2014). Angstens røtter: eksistensiell forståelse og mestring. Fagbokforlaget

Pekrun, R., Goetz, T., Daniels, L. M., Stupnisky, R. H., \& Perry, R. P. (2010). Boredom in Achievement Settings: Exploring Control-Value Antecedents and Performance Outcomes of a Neglected Emotion. Journal of Educational Psychology, 102(3), 531549. doi:10.1037/aoo19243

Pekrun, R., Goetz, T., \& Perry, R. (2005). Academic emotions questionnaire (AEQ). User's manual. Department of Psychology, University of Munich.

Pekrun , R., Goetz , T., \& Perry , R. (2014). Boredom and Academic Achievement: Testing a Model of Reciprocal Causation. Journal of Educational Psychology, 106(3), 696-710. https://doi.org/10.1037/a0036006

Pekrun , R., Goetz , T., Titz , W., \& Perry , R. (2002). Achievement Emotions in students ` Self-Regulated learning and achievement: A program of qualitative and quantitative research. Educational Psychology, 37(2), 91-105.

Pettersen, R. C. (2017). Problembasert læring for studenter og lærere: introduksjon til PBL og studentaktive læringsformer (3. utg. ed.). Universitetsforlaget. 
The impact of emotions on learning and motivation in producing and presenting digital stories

Price, D. M., Strodtman, L., Brough, E., Lonn, S., \& Luo, A. (2015). Digital Storytelling: An Innovative Technological Approach to Nursing Education. Nurse Educator, 40(2), 66-70. https://doi.org/10.1097/NNE.0000000000000094

Reeves, T. (2011). Can educational research be both rigorous and relevant. Educational Designer, 1(4), 1-24.

Ribeiro, S. P. M., Moreira, A. A. F. G., \& da Silva, C. M. F. P. (2016). Digital storytelling: Emotions in higher education. In J. M. Spector, D. Ifenthaler, D. G. Sampson, \& P. Isaias (Eds.), Competencies in Teaching, Learning and Educational Leadership in the Digital Age : Papers from CELDA 2014: Springer International.

Ryan, R. M., \& Deci, E. L. (2012). Motivation, Personality, and Development Within Embedded Social Contexts: An Overview of Self-Determination Theory (1 ed.): Oxford University Press.

Ryan, R. M., Deci, E. L., Fowler, R. D., Seligman, M. E. P., \& Csikszentmihalyi, M. (2000). Self-Determination Theory and the Facilitation of Intrinsic Motivation, Social Development, and Well-Being. American Psychologist, 55(1), 68-78. doi:10.1037/0003-066X.55.1.68

Sandars, J., \& Murray, C. (2011). Digital storytelling to facilitate reflective learning in medical students. Medical Education, 45(6), 649. https://doi.org/10.1111/i.13652923.2011.03991.x

Schjelde, T. J. (2015). Hvordan føles det?; om forholdet mellom følelser og læring. Bedre skole (1), 57-59.

Stacey, G., \& Hardy, P. (2011). Challenging the shock of reality through digital storytelling. Nurse Education in Practice, 11(2), 159-164. https://doi.org/10.1016/..nepr.2010.08.003

Trigwell, K., Ellis, R. A., \& Han, F. (2012). Relations between Students' Approaches to Learning, Experienced Emotions and Outcomes of Learning. Studies in Higher Education (7), 811-824. doi:10.1080/03075079.2010.549220 